\title{
SURVIVAL OF RODENT MALARIA MEROZOITES IN THE LYMPHATIC NETWORK: POTENTIAL ROLE IN CHRONICITY OF THE INFECTION
}

\author{
LANDAU I.*, CHABAUd A.G.*, MORA-SILVERA E.*, COQUElin F.*, BOUlARD Y.*, RÉNIA L.** \& SNOUNOU G.***
}

\begin{abstract}
Summary :
Experiments performed during the last few years, lead us to hypothesise the existence of latent asexual forms of murine Plasmodium. In the present report we examined the organs of infected animals and describe novel structures, which we call merophores, containing merozoites which have resisted lysis seen with other asexual stage parasites. We propose that these merozoites represent a latent form of the parasite. Merophores were also found in the lymphatic circulation, and were demonstrated by subinoculation to have retained their viability. Depending on the parasite species two types of merophores were observed. For $P$. yoelii nigeriensis merophore sacks, with the latent merozoites found inside vesicles, were usually observed.

Merophore leucocytes, where latent merozoites dispersed in the cytoplasm of macrophages or neutrophils, were solely seen with $P$. vinckei petteri. Both structures were seen in $P$. chabaudi chabaudi infections. Merophores were found in lymph nodes of rodents after the asexual parasitaemia had apparently subsided. They were formed soon after schizogony, principally in the spleen, either by pitting or by macrophage phagocytosis. Merophore numbers appeared to be proportional to the number of maturing schizonts. We propose that merophore formation and their circulation in the lymphatics play an important role in the pattern of recrudescences and chronicity of rodent malaria infections. It is further suggested that the lymphatic network, a privileged pathway for many parasites, might play a similar role in human malaria infections.
\end{abstract}

KEY WORDS : chronicity, latency, lymphatic, merophore, merozoite, Plasmodium chabaudi, Plasmodium vinckei, Plasmodium yoelii, recrudescence.

\section{INTRODUCTION}

$\mathrm{I}$ $\mathrm{n}$ the natural host Thamnomys rutilans, the course of malaria infections is characteristically chronic and life-long. For instance all the Thamnomys older

\footnotetext{
* Laboratoire de Biologie Parasitaire et Laboratoire de Protozoologie et Parasitologie Comparée (EPHE), Muséum National d'Histoire Naturelle, 61, rue Buffon, 75231 Paris Cedex 05, France.

** U 445 INSERM, Institut Cochin de Génétique Moléculaire, Hôpital Cochin, Bâtiment Gustave Roussy, 27, rue du Faubourg SaintJacques, 75014 Paris, France.

*** Department of Infection and Tropical Medicine, Imperial College School of Medicine, Northwick Park Hospital, Harrow, Middlesex HA1 3UJ, United Kingdom.

Correspondence: Irène Landau.

Tel.: (+33) (1) 40793500 - Fax: (+33) (1) 40793499.

e-mail: landau@mnhn.fr
}

Résumé : SURVIE, DANS LE RÉSEAU LYMPHATIQUE, DES MÉROZOÏTES DES PLASMODIUMS MURINS. RÔle PROBABLE DANS LA CHRONICTTÉ DE L'INFECTION Les travaux poursuivis au cours des récentes années sur le paludisme des rongeurs nous ont conduit à supposer l'existence de mérozoites latents. Dans les appositions ou les coupes de différents organes des rongeurs infectés, il existe des structures, non encore décrites, que nous nommons mérophores. Ces structures contiennent des mérozoïtes qui ont résisté à la lyse observée avec les autres formes parasitaires. Dans nos hypothèses ces mérophores constituent des formes de latence du parasite. Ils se trouvent dans le réseau lymphatique et, comme l'indiquent les subinoculations ils conservent leur infectivité. Selon l'espèce plasmodiale étudiée deux types morphologiques sont observés: "Sacs mérophores" presque toujours pour P. yoelii nigeriensis, avec les mérozoiltes latents rassemblés dans une vésicule, ou "leucocytes mérophores" presque toujours pour $\mathrm{P}$. vinckei petteri, avec les mérozoites latents dispersés dans le cytoplasme d'un neutrophile ou d'un macrophage. Les deux types de formations coexistent pour P. chabaudi chabaudi. Des mérophores ont été observés dans les ganglions lymphatiques de rongeurs après la disparition des stades asexués du sang. Ils se forment peu après la schizogonie, essentiellement dans la rate, soit par "pitting" soit par phagocytose des macrophages. Le nombre de mérophores semble proportionnel à l'intensité de la schizogonie. Nous pensons que la formation et la circulation des mérophores dans le réseau lymphatique jove un rôle essentiel dans la chronicité et les rythmes de recrudescences particuliers à chaque espèce de Plasmodium murin. Il est suggéré que le réseau lymphatique, refuge privilégié de nombreux parasites, joue un rôle comparable dans les paludismes humains.

MOTS CLÉS : chronicité, latence, lymphatique, mérophore, mérozoïte, Plasmodium chabaudi, Plasmodium vinckei, Plasmodium yoelii, recrudescence.

than two months, captured during March-April 1965 and 1966 at the experimental field station of La Maboké near M'Baiki (Central African Republic), were found to be infected with one or more Plasmodium species, with the parasitaemia mostly $<0.01 \%$ and never more than $3 \%$. When maintained in captivity, these wild caught Thamnomys maintained low-grade infections which persisted all their life (up to two years) (Landau \& Chabaud, 1994b). In a later study the course of infection of two T. rutilans captured in the Central African Republic and kept in captivity in Paris, was followed for 17 month by carrying out subinoculations every 15 days (Landau \& Gautret, 1998). The three parasite species, which naturally co-exist in this host, each presented a characteristic course of infection. P. chabaudi chabaudi was almost always found (9/10 subinoculations), while $P$. vinckei petteri was detected 
nearly every other inoculation. $P$. yoelii nigeriensis on the other hand remained undetectable for five months and then could only be observed in only one of the two Thamnomys but only in one of four subinoculations (Landau \& Gautret, 1998).

When laboratory born T. rutilans were experimentally infected with either one of the above three parasite species, and the course of infection followed for 12 to 58 weeks by subinoculation, the infections presented a similar course to that observed in wild caught animals. The parasitaemias reached a peak of $3 \%$ or less, and the chronicity of the infection and the pattern of recrudescences were also found to be similar to those observed with natural infections. The fact that comparable results were obtained when the animals were inoculated with sporozoites or with fresh infected blood, strongly suggested that the different patterns of recrudescences were due to erythrocytic parasites, and could be accounted for by postulating the existence of latent parasites, i.e. parasites which survive for extended periods before initiating further cycles of replication.

We had previously demonstrated the existence of latent merozoites in murine malaria parasites through a number of biological observations (summarised by Landau \& Chabaud, 1994a). The selective resistance of merozoites over other asexual blood stages to cryopreservation (Montalvo et al., 1988), was exploited to confirm that red blood cell (RBC) invasion can be delayed by 12 to 18 hours following inoculation of $P$. y. nigeriensis or $P$. c. chabaudi merozoites (Landau \& Chabaud, 1980). The presence of such forms in the blood could not however be demonstrated with ease during an ongoing infection. The observation of Plasmodium parasites in the lymphatic circulation (Landau et al., 1995) suggested a mechanism for the localisation and survival of such latent merozoites.

In the present work detailed investigation of various organs and of their lymphatic network resulted in the detection of latent merozoites in animals infected with each of three different rodent Plasmodium species. Depending on the parasite species, these latent forms occurred either as "merophore leucocytes", where the merozoites were dispersed separately in the cytoplasm of a macrophage or neutrophil, or as "merophore sacks", where the occasionally numerous merozoites were gathered inside a vesicle. Viability of these latent merozoites was confirmed by subinoculation of lymphatic fluid.

Confirmation that malaria parasites can survive as latent forms possibly in the lymphatic circulation suggests a mechanism for recrudescences and for the chronicity of infections, and has implications to the interpretation of drug resistance studies.

\section{MATERIALS AND METHODS}

BIOLOGICAL MATERIAL

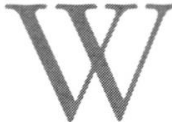

hite male mice IOPS OF1 (Swiss IFFACredo, France) weighing between 20 and 25 grams were used. Some mice, infected by $P$. y. nigeriensis, were splenectomised at D5 (postinoculation). Infections were also analysed in Wistar outbred rats (Charles Rivers).

Three species of murine malaria parasites were used Plasmodium chabaudi chabaudi, strain 864 VD, Plasmodium vinckei petteri, strain $106 \mathrm{HW}$ and Plasmodium yoelii nigeriensis.

\section{OBSERVATION METHODS}

Optical microscopy was used for the observation of merophores which are only easily detectable in impression smears from various organs: liver, spleen, bone marrow, kidney, brain, and with the renal, mediastinal, lumbar and mesenteric lymph nodes. These smears were fixed by Bouin's fluid and stained by the Giemsacolophonium method. Some sections of lymphoid organs fixed with Carnoy's fluid were stained with the Giemsa-colophonium method. The ultrastructural observations were performed according to Seureau et al. (1980).

\section{PARASITE ENUMERATION}

As indicated below, the merozoites are rarely free, and are mostly to be found either dispersed in the cytoplasm of a leucocyte (merophore leucocyte), or gathered inside a transparent generally spherical sack (merophore sack). Estimation of the number of merophores in the spleen and the lymph nodes, is difficult because the impression smears are not homogenous and only an approximation of their numbers can be given. The smears and the sections were examined with the help of an ocular reticule. Fields of equivalent thickness were selected, i.e. with roughly the same numbers of cells. The following approximations were made. a) Merophore sacks: for 100 grids inspected, an average of 17,000 nuclei were counted for the impression smears of the spleen. A comparable number of nuclei was counted in sections, $5 \mu \mathrm{m}$ thick, with 50 grids. The volume corresponding to 50 grids of sections is $100 \times 100 \times 5 \times 50=2.510^{6} \mu^{3}$. A spleen of $1 \mathrm{~g}$, approximately $1 \mathrm{~cm}^{3}$ or $1,012 \mu \mathrm{m}^{3}$, thus contains $10^{12} / 2.5 \times 10^{6}$ or 400,000 cells. Thus when one merophore sack per 100 grids is found, a mouse spleen weighing $0.2 \mathrm{~g}$, was estimated to contains 80,000 sacks, and b) merophore leucocytes: in spleen impression smears the percentage of neutrophil and macrophage latent merozoite carriers was calculated in relation to the total number of neutrophils. 


\section{SAMPLING OF LYMPH}

The lymph was sampled from the intestinal lymph canal (ILC) which drains the lymph from the liver, the mesentery, part of the intestine, several lymph nodes and the spleen, a particularly important organ. It is necessary to handle the vessel without provoking the slightest haemorrhage, and this was verified by examination of the smeared and Bouin-fixed Giemsastained cellular pellet obtained after centrifugation of the samples in micro-haematocrit tubes. Catheterisation of the intestinal lymph canal was performed using the surgical technique described by Waynforth (1980). In order to best visualise the lymph vessel the rat was given $0.8 \mathrm{ml}$ of olive oil one hour before the operation.

The lymph collected was diluted in saline and a given volume was inoculated intra-peritoneally to mice. Daily blood smears were performed and the time to reach a parasitaemia of $5 \%$ was recorded in order to evaluate the numbers of infective stages present in the inoculum. The calculation was based on the results of Beauté-Lafitte et al. (1993) where the number of hours necessary for $P$. y. nigeriensis to reach a parasitaemia of $5 \%$ was determined for inocula of increasing dilutions of freeze-thawed infected blood. According to these authors a $5 \%$ parasitaemia is reached only 160 hours after a single merozoite is inoculated.

A ligature of the ILC was performed in one rat and five mice to study its contents histologically. The rodents were given olive oil, one hour before the operation, anaesthetised and the ILC exposed. Two ligatures were performed approximately $1 \mathrm{~cm}$ apart and the mouse was sacrificed by $\mathrm{CO}_{2}$ inhalation. It was then immersed into Carnoy's fixative during one hour before the ILC was removed, transferred into Carnoy's fixative for a further twelve hours, and processed for histology.

\section{RESULTS}

\section{MEROPHORES}

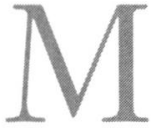

erophores were mainly observed at the end of schizogony when the leucocytes scavenge in the organs where parasite maturation takes place, that is in all the viscera. The highest concentration of merophores was seen in the spleen. Latent merozoites appeared in different forms. Some occurred as a few dispersed units inside a leucocyte which may be a macrophage or a polymorph, and some were enclosed in merophore sacks. The number of merozoites and pigment masses contained in merophore sacks indicate that some contained more than one schizont. These merophore sacks appear mostly extra-cellular and were very likely formed inside macrophages which have lysed.

\section{Merophore sacks}

Optical microscopy showed the merophore sack (Figs 1A-E, 2A, 2C, 2E, 3A, 4A-B) as a clear rounded structure, which contained one or several mature and ruptured schizonts. It was found inside a macrophage or was frequently extra-cellular. The merozoites were dispersed in the interior of the cavity with one to three pigment masses. Up to 40 merozoites may be seen inside the sack. The pigment masses were identical to those observed in the mature schizonts of the blood. There was no sign of degeneration or digestion. Other phagocytosed elements in the process of being digested, were sometimes present elsewhere in the host cell.

The merophore sacks differed from schizonts seen digested in macrophages by their smooth rounded contour, by the regular dispersion of merozoites inside a transparent cavity, and by their healthy appearance and normal staining affinities.

When the merophore sacks were extra-cellular, either because the macrophage was dead or because it mechanically burst when the smear was performed, their morphology was distinct from that of schizonts inside red blood cells: the vesicles were apparently empty apart from the merozoites and a few pigment granules. The number of merozoites and pigment masses was an indication of the number of mature schizonts assembled in the sack. The host cell membrane was stained by the antibody Mac-2 (Mora-Silvera et al., 1997), thus confirming that the host cell belongs to the monocyte-macrophage line.

In the red pulp of the spleen of mice infected with $P . y$.nigeriensis, electron microscopy revealed the following. a) an extra-cellular immature merophore sack which was a round structure, 6-7 $\mu \mathrm{m}$ diameter, containing several merozoites and one or two pigment granules. The parasitophorous vacuole, which was present and surrounded by remains of the erythrocytic cytosol, was very vacuolated and slightly electron dense. The whole was surrounded by the red blood cell external membrane (Fig. 5A). The merozoites were of average electron density, possessed typical structures (rhoptries and dense micronemes, homogenous nucleus, dense cytoplasm), and were healthy in appearance. $b$ ) Merophore sacks in which the membrane of the parasitophorous vacuole had ruptured, releasing the merozoites into the ghost of the red cell. The cytosol of the erythrocyte had disappeared and the only limiting membrane was the envelope of the red blood cell (Fig. 5B). c) We have also observed a macrophage containing at least seven merozoites inside a phagocytic vacuole limited by a single membrane. 


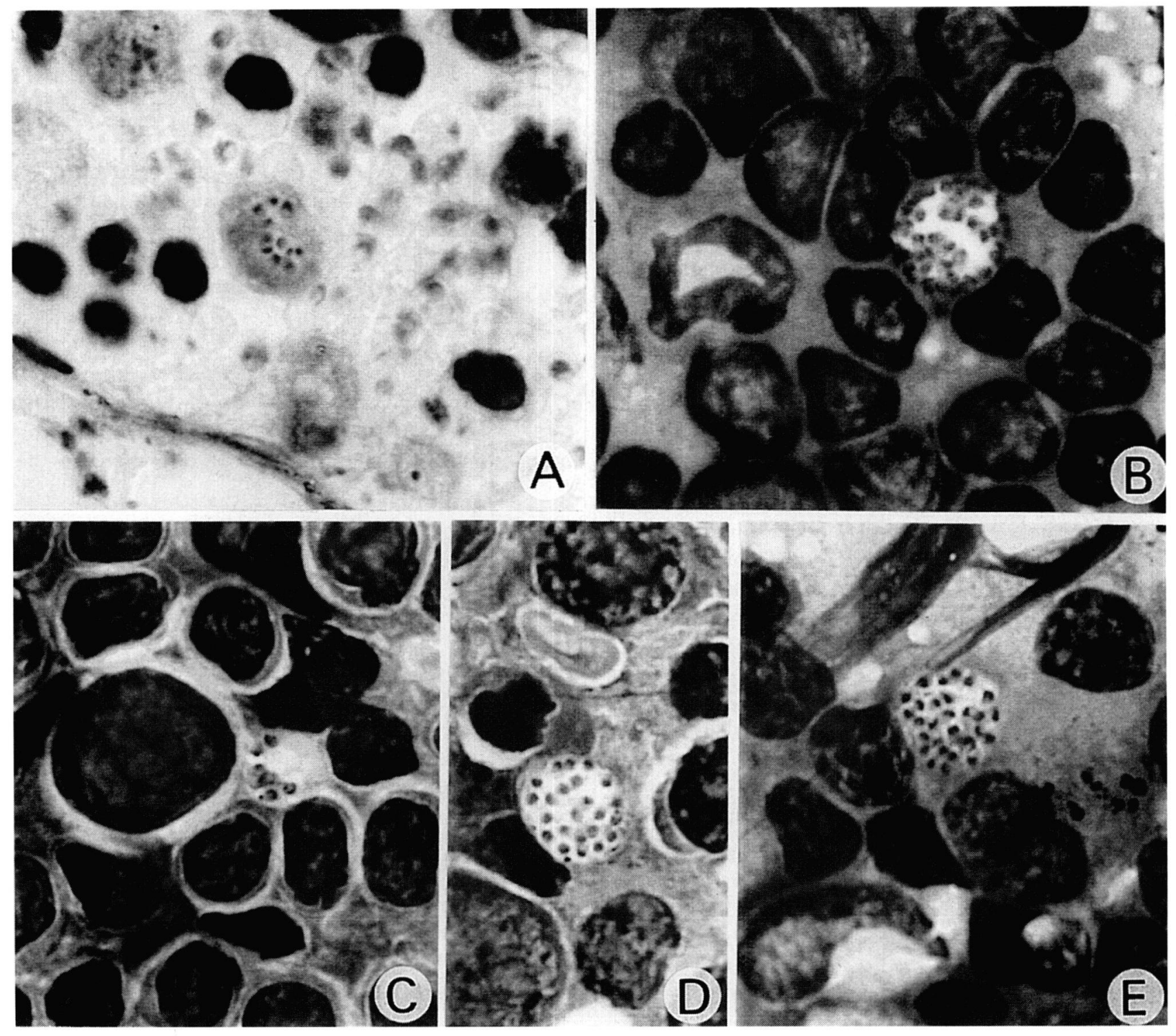

Fig. 1. - Merophore sacks of Plasmodium yoelii nigeriensis. Impression smears (except A: section) Giemsa-colophonium $(\times 1,750)$. PI $=$ postinoculation.

A) Splenectomised mouse. Day 5 (PI). Parasitaemia $33 \%$. Merophore sack inside a leucocyte, in the cortical sinus of a renal lymph node. B) Splenectomised mouse. Day 5 (PI). Parasitaemia $33 \%$. Merophore sack containing approximately 40 merozoites in a renal lymph node

C) Mouse day 25 (PI). Parasitaemia $0.07 \%$. Merophore sack in a renal lymph node.

D) Mouse day 6 (PI). Parasitaemia $26 \%$. Merophore sack in the spleen.

E) Mouse day 4 (PI). Parasitaemia $53 \%$. Merophore sack in a mediastinal lymph node.

These merozoites looked healthy by contrast with the degenerated aspect of the leucocyte which showed the beginning of cytoplasmic vacuolisation, rupture of the nuclear envelope, and a homogenous and granular nucleus (Fig. 5C, the leucocyte is in the process of being phagocytised by a neighbouring macrophage).

Merophore leucocytes

By optical microscopy some merozoites were observed inside macrophages and neutrophils of the spleen, the lymph nodes and even, sometimes of the blood
(Figs 2B, 2D, 2F, 3B-D). One to ten of these merozoites were dispersed in the cytoplasm of the host cell which sometimes also contained one or two pigment granules. The host cell and the merozoites were apparently intact.

Merophores isolated inside leucocytes were observed by electron microscopy during an ultrastructural study of the spleen of a mouse infected by $P . v$. petteri (Fig. 5D). They appeared as round phagocytic vacuoles, each containing a single merozoite and limited by a single membrane more or less applied against the 

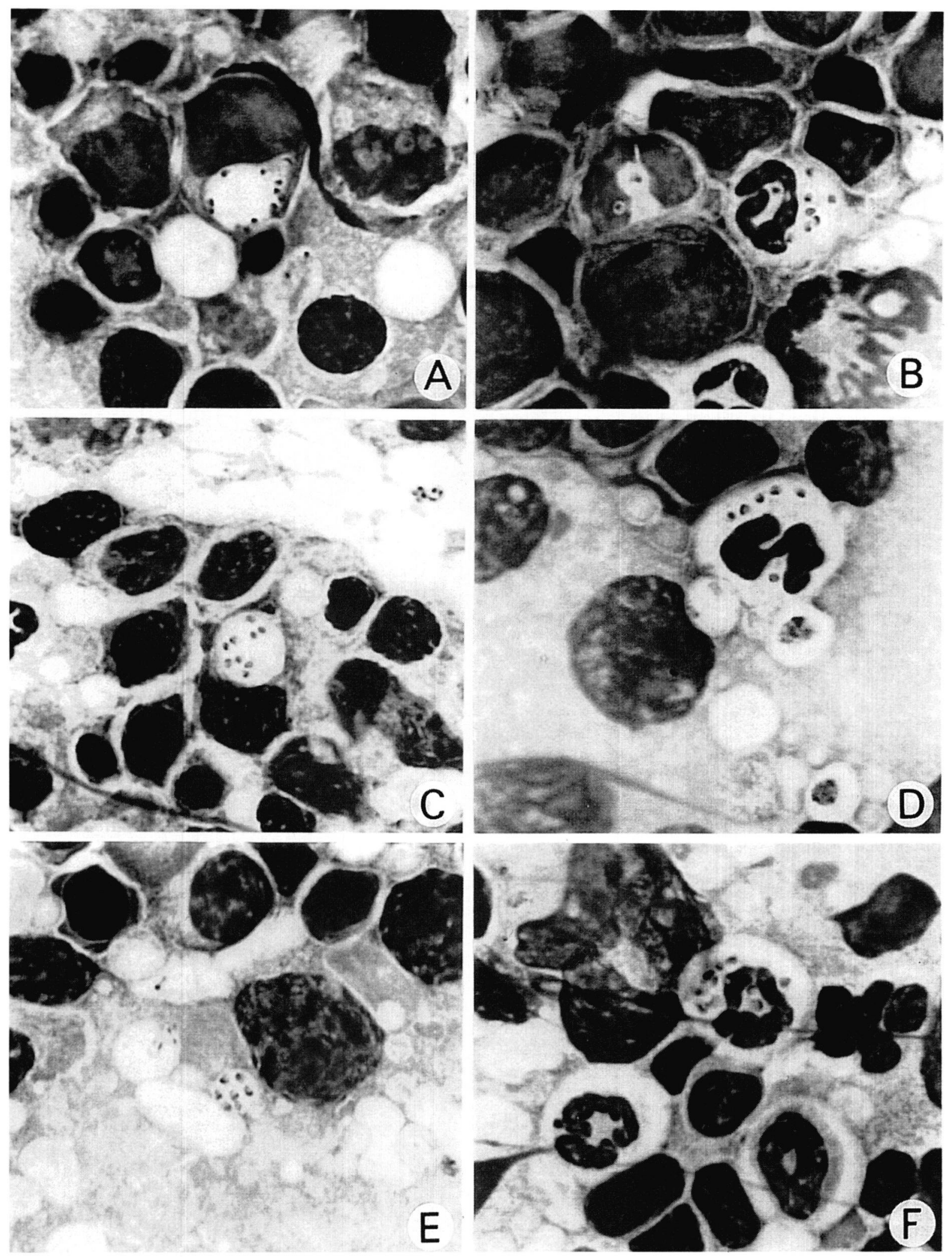

Fig. 2. - Merophores of P. c. chabaudi in the spleen. Impression smears. Giemsa-colophonium $(\times 1,750)$.

A) Mouse day 13 (PI). Parasitaemia $16 \%$. Merophore sack inside a macrophage in the spleen.

B) Mouse day 14 (PI). Post-crisis. Parasitaemia $20 \%$. Left, merophore leucocyte (macrophage); right, merophore leucocyte (polymorph).

C) Same mouse as B. Merophore sack inside a macrophage.

D) Mouse day 12 (post-inoculation). Parasitaemia $26 \%$. Merophore leucocyte (polymorph).

E) Mouse day 14 (PI). Parasitaemia $20 \%$. Merophore sack inside a macrophage in the spleen.

F) Mouse day 11 (PI). Parasitaemia $8 \%$. Merophore leucocyte (polymorph). 


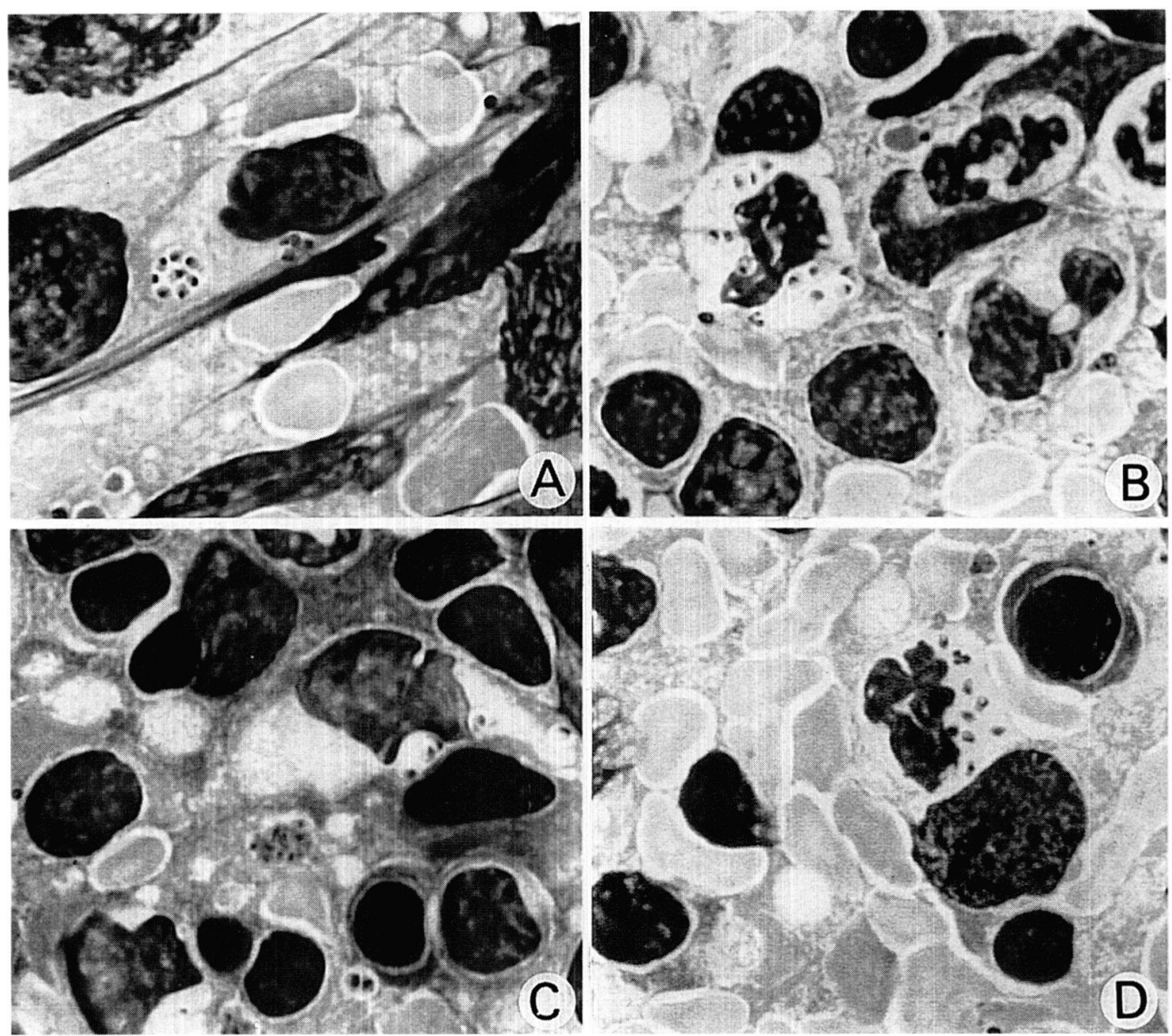

Fig. 3. - Merophores of P. vinckei petteri in the spleen. Impression smears. Giemsa-colophonium ( $\times 1,750)$.

A) Mouse day 7 (PI). Parasitaemia $21 \%$. Merophore sack inside a macrophage in the spleen.

B) Mouse day 8 (PI). Parasitaemia $16 \%$. Merophore leucocyte (polymorph).

C) Mouse day 8 (PI). Parasitaemia $45 \%$. Merophore leucocyte (macrophage)

D) Mouse day 8 (PI). Parasitaemia $45 \%$. Merophore leucocyte (polymorph).
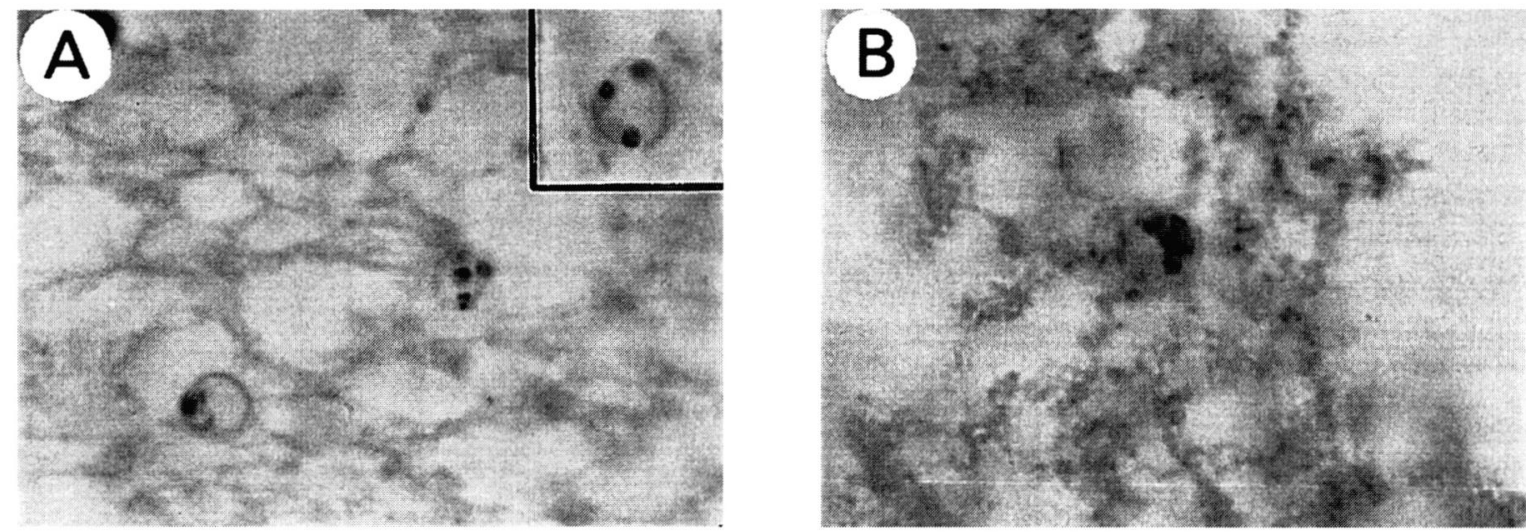

Fig. 4. - Section of merophores of $P$. y. nigeriensis inside the intestinal lymph canal of mice fixed in situ after ligature. Sections. Giemsacolophonium $(\times 1,750)$

A) P. y. nigeriensis left, red blood cell parasitized by a trophozoite and merophore sack with three merozoites. Insert: same merophore, in the adjacent section with three other merozoites.

B) P. y. nigeriensis. Merophore sack. 

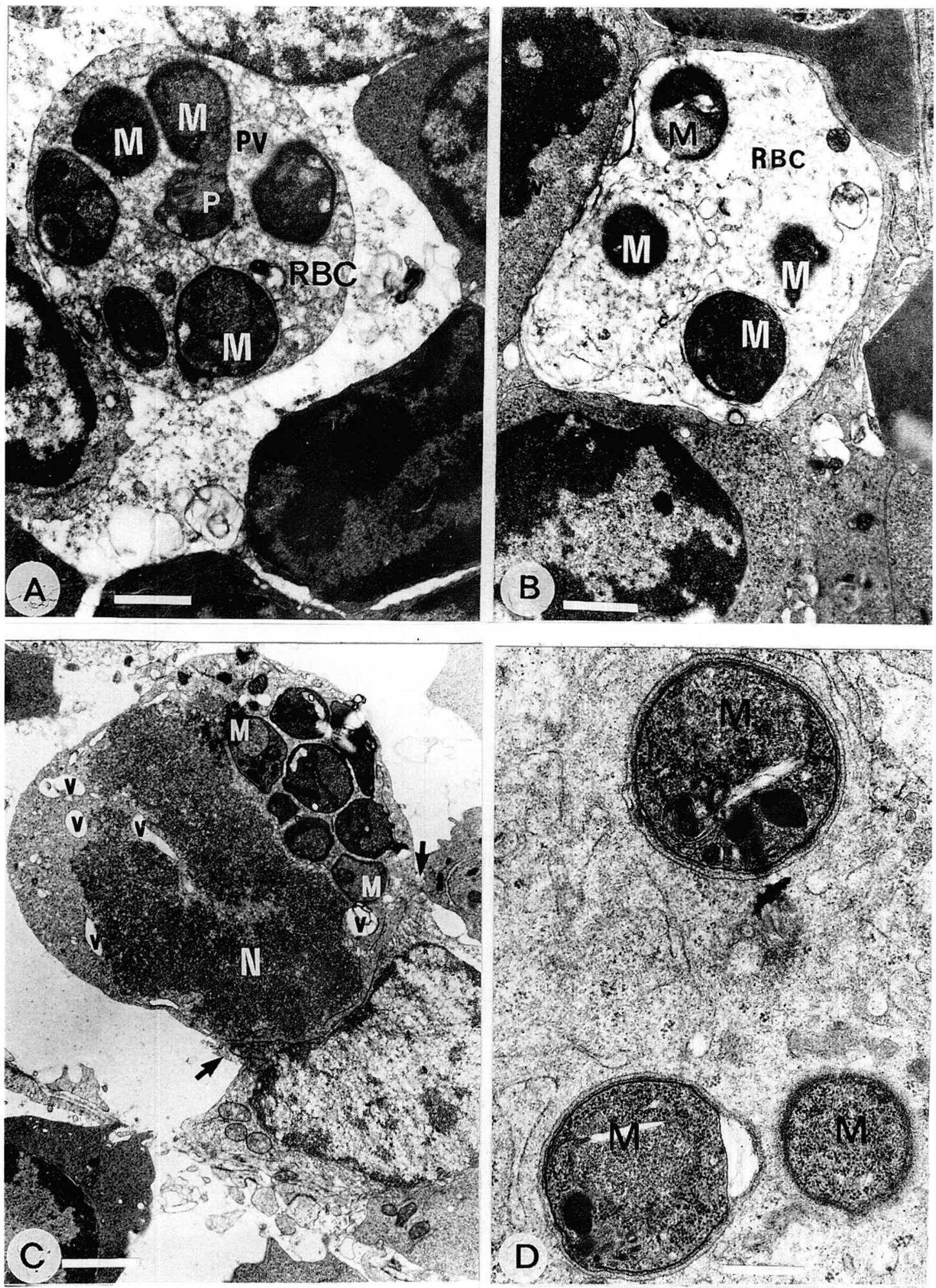

Fig. 5. - Transmission electron microscopy of merophores.

A) Merophore formation of $P$. y. nigeriensis. Six merozoites (M) (one of them still attached to the pigment granule) are enclosed in a common parasitophorous vacuole (PV) inside a red blood cell (RBC) with a vacuolated cytosol ( $\times 140,000)$.

B) Merophore sack of $P . y$. nigeriensis with four sections of scattered merozoites. Of the red blood cell (E) only the plasmic membrane remains $(\times 15,000)$.

C) Macrophage with eight merozoites of $P$. y. nigeriensis inside a phagosome. The host-cell ( $\mathrm{N}$ nucleus, $\mathrm{V}$ vacuoles) is in the process of being destroyed by another macrophage; note the pseudopodia (arrow) of the other macrophage.

D) Merophore macrophage of $P . v$. petteri (M). Note the unaltered appearance of the parasite organelles and the absence of lysosomes around the merozoites and inside the cytoplasm of the macrophage $(\times 3,000)$ 
merozoite. The intermembrane space was electron clear, containing little or no material. Up to five of these vacuoles could be found per leucocyte section. Each contained one unaltered merozoite with easily recognisable organelles.

These structures differed from the merozoites in the course of elimination. The latter were electron dense with altered organelles. They were inside a phagosome, in close contact with primary lysosomes which discharged an electron dense material filling the phagolysosomal cavity thus formed.

\section{SPECIFIC LOCALISATION AND ABUNDANCE OF THE MEROPHORES}

The localisation and abundance of merophores varied from one species to the other. Results are presented in the following tables. Table I: P. y. nigeriensis in the spleen, Table II: $P$. y. nigeriensis extrasplenic, Table III: P. c. chabaudi, and Table IV: P. v. petteri.

P. y. nigeriensis (Fig. 1) gave rise to numerous merophore sacks, with large, round merozoites, often extracellular. Merophore leucocytes were exceptional.

\begin{tabular}{|c|c|c|c|}
\hline Rodent & Day & $\% \mathbf{P}$ & MS \\
\hline 1 & 1 & 0 & 0 \\
\hline 2 & 2 & 0.13 & 0 \\
\hline 3 & 3 & 0.40 & 0 \\
\hline 4 & 3 & 14 & 3 \\
\hline 5 & 3 & 21 & 33 \\
\hline 6 & 3 & 26 & 30 \\
\hline 7 & 3 & 27 & 17 \\
\hline 8 & 3 & 30 & 3 \\
\hline 9 & 4 & 5 & 15 \\
\hline 10 & 4 & 30 & 0 \\
\hline 11 & 4 & 53 & 18 \\
\hline 12 & 5 & 19 & 40 \\
\hline 13 & 6 & 8 & 0 \\
\hline 14 & 6 & 26 & 61 \\
\hline 15 & 7 & 9 & 40 \\
\hline 16 & 7 & 17 & 0 \\
\hline 17 & 7 & 40 & 9 \\
\hline 18 & 8 & 34 & 25 \\
\hline 19 & 11 & 52 & 4 \\
\hline 20 & 12 & 75 & 6 \\
\hline 21 & 12 & 103 & 4 \\
\hline 22 & 18 & 40 & 10 \\
\hline 23 & 25 & 0.07 & 1 \\
\hline 24 & 8 & 19 & 6 \\
\hline 25 & 10 & 28 & 3 \\
\hline 26 & 17 & $28(\mathrm{pc})$ & 5 \\
\hline 27 & 17 & $44(\mathrm{pc})$ & 6 \\
\hline 28 & 20 & $18(\mathrm{pc})$ & 4 \\
\hline
\end{tabular}

Day: day of autopsy (post-inoculation). \% P: parasitaemia. (pc): postcrisis. MS: number of merophore sacks counted on 100 reticular grids of impression smears.

Table I. - Abundance of merophore sacks in the spleen of mice infected with $P$. yoelii nigeriensis.

\begin{tabular}{cccc}
\hline Rodent & Day & \% $\mathbf{P}$ & Organ \\
\hline 29 & 3 & 15 & mediast. 1. n. \\
30 & 4 & 51 & renal 1. n. \\
31 & 4 & 51 & renal $1 . \mathrm{n}$. \\
31 & 4 & 51 & mesent. 1. n. \\
31 & 4 & 51 & lumbar l. n. \\
11 & 4 & 53 & mediast. 1. n. \\
11 & 4 & 53 & bone marrow \\
32 & 5 & 33 & renal 1. n. \\
33 & 5 & 44 & myocardium \\
34 & 6 & 67 & bone marrow \\
15 & 7 & 9 & brain \\
23 & 25 & 0.07 & renal l. n. \\
35 & 27 & 0 & blood \\
\hline
\end{tabular}

Day: day of autopsy (post-inoculation). \% P: parasitaemia. 1. n. : lymph node. mediast.: mediastinal. mesent.: mesenteric.

Table II. - Extrasplenic merophore sacks detected in mice infected with $P$. yoelii nigeriensis.

\begin{tabular}{rccrr}
\hline Mouse & Day & \% P & MS & ML \\
\hline 1 & 11 & 8 & 5 & 20 \\
2 & 12 & 26 & 23 & 20 \\
3 & 12 & $>50$ & 0 & 4 \\
4 & 13 & 28 & 0 & 3 \\
5 & 13 & 41 & 8 & 2 \\
6 & 13 & 75 & 3 & 10 \\
7 & 13 & 76 & 5 & 2 \\
8 & 14 & 1 & 0 & 0 \\
9 & 14 & 27 & 6 & 2 \\
10 & 14 & 51 & 10 & 1 \\
11 & 14 & $20(\mathrm{pc})$ & 3 & 1 \\
12 & 15 & $17(\mathrm{pc})$ & 3 & 1 \\
\hline
\end{tabular}

Day: day of autopsy (post-inoculation). \% P: parasitaemia. (pc): postcrisis. MS: number of merophore sacks counted on 100 reticular grids of impression smears of the spleen. ML: number of merophore leucocytes per 1,000 leucocytes.

Table III. - Abundance of merophore sacks and merophore leucocytes in the spleen of mice infected with $P$. chabaudi chabaudi.

\begin{tabular}{rrrr}
\hline Mouse & Day & \% P & ML \\
\hline 1 & 6 & 1 & 10 \\
2 & 7 & 4 & 50 \\
3 & 8 & 8 & 50 \\
4 & 8 & 9 & 50 \\
5 & 8 & 16 & 40 \\
6 & 8 & 17 & 40 \\
7 & 8 & 45 & 40 \\
8 & 9 & 32 & 10 \\
9 & 9 & 66 & 80 \\
10 & 9 & $>80$ & 20 \\
11 & 10 & 31 & 20 \\
12 & 11 & 4 & 80 \\
13 & 11 & 12 & 80 \\
14 & 11 & 15 & 0 \\
15 & 12 & 2 & 0 \\
16 & 12 & 11 & 20 \\
17 & 13 & 33 & \\
\hline
\end{tabular}

Day: day of autopsy (post-inoculation). \% P: parasitaemia. ML: number of merophore leucocytes per 1,000 leucocytes.

Table IV. - Abundance of merophore leucocytes in the spleen of mice infected with $P$. vinckei petteri. 
P. c. chabaudi (Fig. 2) showed fewer merophore sacks, with round and small merozoites, often disposed peripherally. They were found intracellularly more often than those of $P$. $y$.nigeriensis. The merophore macrophages were small and rounded and usually contained a naked schizont with a pigment grain in its centre. P. v. petteri (Fig. 3) hardly ever showed merophore sacks. The merophores were mostly in neutrophils and seldom in macrophages.

\section{LYMPHATIC CIRCULATION}

Catheterisation and lymph inoculation

One mouse infected with $P . y$. nigeriensis and ten rats infected by either $P . y$. nigeriensis (eight rats), or $P$. berghei (two rats) were successfully operated on. Half of the lymph drawn was inoculated into mice and the inoculum proved to be infective nine times out of eleven. Using the tables established by Beauté-Lafitte et al. (1993) based on the length of the prepatent period, the quantity of merozoites inoculated was estimated at between 50 and 2,500 merozoites per $\mathrm{ml}$ of lymph (Table V).

\begin{tabular}{lcccc}
\hline Rodent & Strain & $\mathbf{\%} \mathbf{P}$ & Day & Nb. $\mathbf{M} / \mathbf{m l}$ \\
\hline Rat 1 & P. y. nig. & 2 & $\mathrm{~J} 3$ & $50-100$ \\
Rat 2 & P. y. nig. & 0.10 & $\mathrm{~J} 3$ & 125 \\
Rat 3 & P. y. nig. & 2 & $\mathrm{~J} 7$ & 2,000 \\
Rat 4 & P. y. nig. & 3 & $\mathrm{~J} 4$ & 0 \\
Rat 5 & P. y. nig. & 20 & $\mathrm{~J} 7$ & $125-1,250$ \\
Rat 6 & P. y. nig. & 4 & $\mathrm{~J} 7$ & $715 / 185-1,850$ \\
Rat 7 & P. y. nig. & 2 & $\mathrm{~J} 8$ & 2,500 \\
Rat 8 & P. y. nig. & 0.20 & $\mathrm{~J} 36$ & $85-800$ \\
\hline Rat 9 & P. b. NK65 & 0.10 & $\mathrm{~J} 6$ & 0 \\
Rat 10 & P. b. ANKA & 26 & $\mathrm{~J} 8$ & 55 \\
\hline Mouse 1 & P. y. nig. & 38 & $\mathrm{~J} 5$ & $100-1,000$ \\
\hline
\end{tabular}

Day: day of autopsy (post-inoculation). \% P: parasitaemia. Nb.M./ml lymph: evaluation of the number of merozoites, per $\mathrm{ml}$ of lymph.

Table V. - Estimation of the number of infective stages in the lymph of the intestinal canal of rodents infected with $P$. yoelii nigeriensis and $P$. berghei.

The number of merozoites peaked shortly before the crisis, when parasite numbers were maximum. However, the numbers of latent merozoites seemed to cumulate with the duration of infection. The lymph of a rat with a low parasitaemia $(0.15 \%), 36$ days post inoculation was shown to be infective.

\section{Ligatures}

Histological observations made on the intestinal lymph canal (ILC) of three mice and one rat infected with $P$. y. nigeriensis (Table VI) showed that it contained a few intra-erythrocytic parasites of all stages, a few free merozoites, and some uninfected RBCs (Fig. 4A). The morphology of the parasitised red blood cell was

\begin{tabular}{lcc}
\hline Rodent & \% P & N \\
\hline Rat 1 & 4 & $0.4-0.5$ \\
\hline Mouse 1 & 24 & 1.7 \\
Mouse 2 & 32 & 2.3 \\
Mouse 3 & 50 & 9 \\
\hline
\end{tabular}

\% P: parasitaemia. N: Number of parasites per 100 leucocytes.

Table VI - Abundance of parasites, at day 6 (post-inoculation), in histological sections of the intestinal lymph canal, of rodents infected with $P$. yoelii nigeriensis.

altered and differed from that of infected cells inside neighbouring blood vessels, in that they were much paler and only a thin surrounding pellicle remained visible.

Some schizonts in the lymph appeared fully mature with well defined merozoites, and a few free merozoites were seen inside the ILC of a mouse. In addition to erythrocytic parasitic stages, rare merophore sacks (Fig. 4B) were identified in sections. However, it is possible that some parasites identified as mature schizonts were in fact free merophore sacks.

In sections of the ILC, parts of the mesenteric and coeliac lymph node were observed. Parasitised RBCs and structures which looked like free or intracellular merophore sacs were sometimes seen in the cortical and cortico-medullar sinuses and in the hylus and the beginning of the efferent lymph vessel.

Ligatures of the ILC of two mice heavily infected ( $49 \%$ and $38 \%$ ) with P. c. chabaudi were performed at midnight (time of schizogony). It appeared that similarly to $P . y$. nigeriensis, the ILC transports erythrocytic stages of $P$. c . chabaudi and altered parasitised erythrocytes. A merophore macrophage with a merozoite inside the cytoplasm was identified in the efferent vessel of the coeliac lymph node.

\section{DISCUSSION}

\section{Chronic INFECTIONS}

I $\mathrm{n}$ their vertebrate hosts malaria parasites survive for extended periods in the face of active immune defences. In the absence of treatment parasites, whose numbers reach a high level during the primary peak which follows inoculation of non-immune hosts, are usually cleared from the circulation by predominantly species and strain-specific immune mechanisms (Talliaferro, 1949; Snounou et al., 1989). The subsequent course of the infection is characterised by the distinct episodes of recrudescence where the parasites reappear in the circulation for short periods, usually at lower levels than in the primary parasitaemia. In a number of natural hosts the infection is thought to be 
life-long, and different Plasmodium species and strains often display a characteristic pattern of recrudescent episodes. Dormant liver stages known as hypnozoites and which account for some of these recurrent episodes, are only found in a few of the primate malaria parasites namely $P$. cynomolgi, $P$. vivax and $P$. ovale, but could not be demonstrated for $P$. falciparum, $P$. malariae (where infections of more than 30 years duration have been recorded), nor for any of the murine Plasmodium species The mechanisms which would explain the phenomenon of protracted recrudescences remain to be elucidated.

Three non-mutually exclusive possibilities could explain the absence of circulating parasites between recrudescences: 1) the number of infected red blood cells is maintained at such low levels, presumably by immune mechanisms, as to make them undetectable by microscopy or even subinoculation, 2) parasites which survive clearance of each parasitaemic wave are sequestered away from the peripheral circulation or 3) the parasite produces latent forms which alone survive clearance, and probably remain sequestered away from the peripheral circulation.

Previous observations of malaria infections in animals models lent support to the continued presence of viable parasites in certain organs following clearance of infected red blood cells from the peripheral circulation (Jerusalem, 1968; Suzuki, 1974). The existence of latent forms of the asexual erythrocytic parasite has been generally considered unlikely. In the absence of drug or immune pressure, parasites in "arrested development" within the red blood cell are yet to be demonstrated. The merozoite was discounted as a candidate since in vitro observations have resulted in the conviction that merozoites would not survive as free cells unless they penetrate erythrocytes within a few minutes of their release from schizonts (Johnson et al., 1980). However, in vivo observations in murine models indicated that invasion by some merozoites can be delayed up to 18 hours, and it was postulated that these merozoites would sequester outside the blood circulation (Landau \& Chabaud, 1994a). Free parasites including merozoites were subsequently demonstrated in the thoracic duct and spleen lymph vessels (Landau et al., 1995), and in the cortical sinus of the renal lymph node (Boulard et al., 1996) of infected mice.

\section{MEROPHORE FORMATION}

In this article we demonstrate that merophores, novel structures containing only merozoites, are formed in some organs but mainly in the spleen, and can be found in the lymphatic circulation where they retain their viability. Merophores were observed with three species of murine Plasmodium.
The formation and quantity of merophore sacks and merophore leucocytes was directly related to the number of mature schizonts in the spleen. The examination of spleen impression smears shortly after the time of schizogony showed intense phagocytosis and the presence of many merophores. Several mechanism can be suggested. Schnitzer et al. (1972, 1973) analysed the various mechanisms of filtration and destruction of parasitised cells in the spleen by electron microscopy. At the end of schizogony, macrophages and neutrophils destroy the altered and infected RBC's, extra-cellular parasites and pigment. However, inspection of impression smears of organs and ultrastructural observations showed that many merozoites remained undamaged and form the specialised structures namely the merophores. Crosby (1957 and 1959) designated the "pitting function of the spleen" as the capacity of this organ to extract inclusions from the RBCs. In order to reach the venous sinuses and the blood circulation erythrocytes trapped inside the splenic cords must proceed through the inter-endothelial slits of the sinus wall. These slits are at the most $0.5 \mu \mathrm{m}$ wide, and only allow the passage of fully deformable erythrocytes. The portion of an infected RBC which contains the parasite may remain outside the sinus while the remainder of the cell goes through the slit. A scission between these two parts occurs and results in the "pitting" of the parasite (Schnitzer et al., 1972, 1973). Merophore sacks which were frequently seen in an extra-extracellular position, may derive from such pitting.

\section{SPECIFIC CHARACTERISTICS OF THE MEROPHORES}

The formation of merophores in the organs of infected animals and their presence in the lymphatic circulation strongly suggests that they represent a latent form of the parasite. We propose that merophores are adaptive structures which ensure the longevity of Plasmodium infections, and explain the recrudescences which characterise the chronic course of these infections.

The different recrudescence patterns which are observed with the three murine Plasmodium species studied appear to correlate with the type of merophores, sack or leucocyte, found and the red blood cell preference of these three parasites. P. yoelii nigeriensis has numerous merophore sacks and practically no merophore leucocytes. This parasite preferentially invades reticulocytes. It may be hypothesised that reticulocytes, which are less motile and more sticky than normocytes (Key, 1921), are readily phagocytosed by macrophages when they contain schizonts of P. yoelii, and thus form the source of the characteristic merophore sacks. Most merophore sacks appear to reach the blood via the lymph canals, but a small number remained inside the lymphatic channels even after the peripheral parasitaemia has cleared. These persisting 
forms might explain the late recrudescences at the lengthy intervals seen in the natural host. By contrast, $P$. vinckei petteri exclusively invades mature cells, and leucocytes would mainly ingest merozoites released from mature schizonts. Indeed this parasites forms practically no merophore sacks and latent merozoites are usually seen dispersed mostly inside neutrophils and sometimes inside macrophages. These merophore leucocytes may explain the frequent early, and the relatively less common late, recrudescences. P. C. chabaudi-infected mice produce equally abundant merophore sacks and merophore leucocytes, and exhibit frequent recrudescences. It is possible that, as the result of the smaller size of $P$. chabaudi mature schizonts (average of six merozoites) and merozoites, the fraction of infected RBC's which go on to form merophores is higher in this species. It is interesting to note that in many instances where highly chronic infections are observed, the size of the schizonts is small, for e.g. $P$. malariae in man, $P$. atheruri in the porcupine (Landau et al., 1983), and P. coulangesi in the Madagascar lemurs (Landau et al., 1989).

\section{CONCLUSION}

T he duration of human malaria infections, including P. falciparum can extend to more than one year, often sub-clinically and despite an effective immune response (Eyles \& Young, 1951; Arez et al., 1999). It has also been noted that sensitive parasites sometimes reappear despite adequate antimalarial treatment (White, 1998). Metabolically inactive drug-resistant merozoites in the merophore would provide an escape mechanism in the face of inhibitory drug levels. Parasites originating from these latent forms could then initiate further waves of parasitaemia. When these recrudescences occur at sub-optimal drug concentrations, the selection of drug resistant parasites would be promoted.

We predict that merophore structures similar to those seen in rodent malaria will be found in Plasmodium species infecting humans and other primates. Histological observations of human infections are for the most part confined to post-mortem samples of pernicious malaria. Observation of infected RBC's in white blood cells would be ascribed to destructive phagocytosis, as development of parasites in these cells is currently excluded. The formation of latent erythrocytic malaria parasites and their trafficking via the lymphatic network have important implications for the interpretation of epidemiological, immunological and clinical observations. Murine malaria infections offer a most suitable system for further studies of these latent forms.
It is interesting to note that mature schizonts of human parasites in white blood cells were described by Bignami in 1890 and Golgi in 1893 (quoted by Thayer, 1901), which prompted them to suggest that late recrudescences might originate from parasites preserved as resistant "spores" in human phagocytes.

\section{ACKNOWLEDGEMENT}

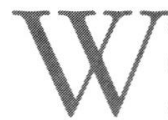
e are particularly grateful to R.J.M. Wilson (NIMR, London) for reviewing the manuscript critically and making excellent improvements.

\section{REFERENCES}

Arez A.P., Snounou G., Pinto J., Sousa C.A., Modiano D., Ribero H., Franco A.S., Alves J. \& Do Rosario V.E. A clonal outbreak Plasmodium falciparum population in an isolated outbreak of malaria in the Republic of Cabo Verde. Parasitology, 1999, 118, 347-355.

Beauté-Lafitte A., Chabaud A., Altemayer-Caillard V., Deharo E., Gautret P. \& Landau I. Schizogonie de Plasmodium yoelii nigeriensis. Rôle des mérozoïtes latents. Annales de Parasitologie bumaine et Comparée, 1993, 68, 211-219.

Beauté-Lafitte A., Altemayer-Caillard V., Gonnet-Gonzalez F., Ramiaramianana L., Chabaud A. \& Landau I. The chemosensitivity of the rodent malarias. Relationships with the biology of merozoites. International Journal for Parasitology, 1994, 24, 981-984.

Coquelin F., Boulard Y., Mora-Silvera E., Richard F., ChaBAUD A.G. \& LANDAU I. Final stage of maturation of the erythrocytic schizonts of rodent Plasmodium in the lungs. Comptes Rendus de l'Académie des Sciences, Sciences de la vie, 1999, 322, 55-62.

Crosby W.H. Siderocytes and the spleen. Blood, 1957, 12, $165-170$

Crosby W.H. Normal functions ot the spleen relative to the blood cells: a review. Blood, 1959, 14, 399-408.

EyLEs D.E. \& Young M.D. The duration of untreated or inadequately treated Plasmodium falciparum infections in the human host. Journal of the National Malaria Society, 1981, 10, 327-336.

Jerusalem C. Active immunisation against malaria (Plasmodium berghei). I. Definition of antimalarial immunity. Zeitschrift für Tropenmedizin und Parasitologie, 1968, 19, 171179.

Johnson J.G., Epstein N., SHIROISHI T. \& Miller L.H. Factors affecting the ability of isolated Plasmodium knowlesi merozoites to attach to and invade erythrocytes. Parasitology, 1980, 80, 539-550.

KEY J.A. Studies on erythrocytes with special reference to reticulum, polychromatophilia and mitochondria. Archive of Internal Medicine, 1921, 28, 511-549. 
LANDAU I. \& Chabaud A.G. Latency of Plasmodium merozoites and drug resistance. A review. Parasite, 1994a, 1, 105-114.

Landau I. \& Chabaud A.G. Plasmodium Species Infecting Thamnomys rutilans: a Zoological Study. Advances in Parasitology, 1994b, 33, 49-90.

Landau I., Chabaud A.G., Vuong P.N., Deharo E. \& Gautret P. Circulation in the lymphatic system and latency of Plasmodium merozoites. Preliminary note. Parasite, 1995, 2, 185-186

LANDAu I. \& Gautret P. Chapter 28. Animal models: Rodents in Malaria: Parasite Biology Pathogenesis and Protection, 1998, I.W. Sherman Edit., ASM Press Washington DC.

Mora-Silvera E., Coquelin F., Vuong P., Deharo E., Gautret P., Renia L., Chabaud A. \& Landau I. Role of macrophages as possible transporters of Plasmodium yoelii nigeriensis merozoites through the lymphatic system. Preliminary note. Parasite, 1997, 4, 83-85.

Schnitzer B., Sodeman T.M., Mead M.L. \& Contacos P.G. Pitting function of the spleen in malaria: ultrastructural observations. Science, 1972, 117, 175-177.

Schnitzer B., Sodeman T.M., Mead M.L. \& Contacos P.G. An ultrastructural study of the red pulp of the spleen in malaria. Blood, 1973, 41, 207-218.

Seureau C., Szollosi A., Boulard Y., landau I. \& Petters W. Aspects ultrastructuraux de la relation hôte-parasite entre le schizonte de Plasmodium yoelii et la cellule hépatique du rat. Protistologica, 1980, 16, 419-426.

SNOUNOU G., JarRa W., VirTyakosol S., WoOd J.C. \& Brown K.N. Use of a DNA probe to analyse the dynamics of infection with rodent malaria parasites confirms that parasite clearance during crisis is predominantly strain- and speciesspecific. Molecular and Biochemical Parasitology, 1989, 37, 37-46.

SuzuKi M. Modification by a latent contaminant of glomerular pathology in mice infected with Plasmodium berghei. Bull. WHO, 1974, 51, 155-165.

TAlliaferro W.H. Immunity to malaria infections. In: Malariology. A comprehensive survey of all aspects of this group of diseases from a global standpoint. (Ed. Mark F. Boyd), 1949, pp. 935-965. W.B. Saunders Company, Philadelphia and London.

THAYER W.S. Lectures on the malarial fevers. 1901, D. Appleton and Company, New York.

Waynforth H.B. Chapter 36. Thoracic duct catheterisation. In: Experimental and Surgical Techniques in the Rat, 1980, Academic Press Ed, London.

WhITE N.J. Why is it that antimalarial drug treatments do not always work? Annals of Tropical Medicine and Parasito$\log y, 1998,92,449-458$.

Reçu le 17 juin 1999 Accepté le 24 septembre 1999 